\title{
ASSESSMENT OF RISK FACTORS AND DETERMINATION OF VACCINE EFFICACY FOR MEASLES OUTBREAK DURING APRIL 2017 IN DHOK KAZIN, ISLAMABAD
}

\author{
Muhammad Wasif Malik ${ }^{182}$, Mumtaz Ali Khan², Muhammad Salman², Muazam Abbas Ranjha ${ }^{2}$, Tayaab Razi \\ Rathore², Urooj Aqeel', Syed ljaz Ali Shah', Mirza Aamir Baig1, Aamer Ikram²
}

${ }^{1}$ Field Epidemiology \& Laboratory Training Program (FELTP), National Institute of Health, Islamabad

${ }^{2}$ National Institute of Health, Islamabad.

Correspondence:drwasifus@yahoo.com

\begin{abstract}
Background: On 13th April 2017, 3 measles cases were reported in Dhok Kazin, Islamabad to National Institute of Health, Islamabad. Federal Disease Surveillance \& Response Unit on request of Islamabad Capital Territory (ICT) health administration started disease outbreak investigation and active case finding. The study was aimed to identify risk factors associated with disease outbreak, to assess vaccine coverage and vaccine efficacy in the outbreak area, and to suggest control measures.

Methods: To determine possible risk factors age and sex matched case-control study was conducted in April, 2017. A case was defined as "Any resident of Dhok Kazin, presented with fever and maculopapular rash with any of signs/symptoms like coryza, conjunctivitis, cough, otitis media or pneumonia after March 20 to April 30, 2017". For each case 04 matched controls were selected. A structured questionnaire prepared to collect data. Vaccine coverage survey was conducted. Uni and multivariate analyses and vaccine efficacy were calculated.

Results: A total of 14 cases identified including 11 cases found on active search. Cases were compared with 57 matched controls. Mean age was 39 months (range 08- 132 months). Among cases male to female ratio observed was 1:2.5. Overall attack rate was $1.2 \%$, while most severely affected age-group was $<12$ months $(A R=10.3 \%)$. The most common complications were diarrhea $n=8(57.1 \%)$ and pneumonia $n=1(7.1 \%)$. On vaccine coverage survey in 230 households, 31(70.5\%) out of 44 children checked were vaccinated. The un-vaccinated children had attack rate of $14.3 \%$ while vaccinated had attack rate of $6.7 \%$. The vaccine efficacy calculated was $53 \%$. Significant association found in risk factors were; contact with positive case [OR 19.5, 95\% Cl; 4.5-84, $\mathrm{P}=0.00$ ], unvaccinated children [OR=10.0, 95\%, Cl;1.2.0-49.3, P=0.003], Mother illiteracy [OR 10.2, 95\% Cl; 2.5-41, P=0.00], Misconception about vaccination [OR $13.2,95 \%, \mathrm{Cl} ; 3.1-57.1, \mathrm{P}=0.00)$, vaccinator not visited home as a part of outreach activity $[\mathrm{OR}=6.4$, $95 \% \mathrm{Cl} ; 1.7-23.4, \mathrm{P}=0.00]$. Reasons for non-vaccination were found to be misconception about vaccination $(\mathrm{OR}=34.8,95 \% \mathrm{Cl}=5.5-219.7)$ and mother's illiteracy $(\mathrm{OR}=6.4,95 \% \mathrm{Cl}=1.2-34.8)$.

Conclusion: Most severely affected age group was 12 months and below. Low immunization rates were the most probable cause of outbreak. Case contacts, partial vaccination, misconception of vaccination, no visit of vaccinator to home, and mother's education were risk factors significantly associated with Measles outbreak. Findings were shared with the district health authorities for implementation of control measures.
\end{abstract}

Keywords: Risk factors, misconception of vaccination, infection control, measles outbreak; vaccination

\section{Introduction}

Measles is an acute viral illness, highly contagious in nature. It is clinically characterized by fever (>101oF), conjunctivitis, coryza, cough, Koplik's spots, and rash on the body. The most commonly reported complication of Measles virus infection includes diarrhea, pneumonia, otits media, and acute encephalitis. The incubation period of Measles, from exposure to prodrome, averages 10-12 days and from exposure to rash onset averages 14 days (range, 7-21 days) (1). The laboratory diagnosis of Measles can be done with confirmation of positive Measles IgM antibodies (2). The case fatality ratio is less than less than $0.01 \%$ in developed countries while it is more than $5 \%$ in developing countries (3). The most effective strategy for prevention and control of Measles is vaccination and because of widespread use of Measles vaccine the morbidity and mortality has been reduced significantly (4). Adverse reactions to Measles vaccination are rare and most common reaction include fever and pain at the site of injection. Potentially lifethreatening side effects occur in less than one per million $(<0.0001 \%)(5)$. Young children are mostly affected by Measles and there were approximately 535,000 deaths of children due to it in 2000 with majority of deaths in 
developing countries. This accounted for $5 \%$ of all cases under five year age mortality (6). There were 192,400 prevalent cases of Measles worldwide in 2013 (7). WHO reported that in 2016 deaths due to Measles were first time fallen below 100,000 per year and estimated to be 89,780 deaths globally. Vaccination against Measles resulted in a drop of $84 \%$ deaths between 2000 and 2016 worldwide (8). In 2016, member countries of Pan American Health Organization / World Health Organization (PAHO / WHO) presented epidemiological evidences before a committee of international experts. The committee after review of the evidence determined that Region of the Americas had eliminated endemic transmission of Measles. This was the first region to achieve elimination this milestone (9).

In Pakistan, Measles virus continues to be a source for disease outbreaks throughout the country. In 2012-13 maximum deaths were experienced in Measles outbreaks from Pakistan as compared to outbreaks of other parts of the world. A total of 321 deaths due to Measles were reported in 2013 (10). While during 2012, a total of 14,000 cases of Measles and 210 deaths were reported in 2012 (11). A major risk factor for Measles outbreak is presence of unvaccinated population in a community and children are most vulnerable for Measles (12). On 13th April 2017, Federal Disease Surveillance \& Response Unit (FDSRU) received information from a private clinician that about 04 clinical suspected cases of Measles in Dhok Kazin, Islamabad. FDSRU responded to the information and informed Field Epidemiology \& Disease Surveillance Division (FEDSD), National Institute of Health (NIH), Islamabad with a request for sharing the same information to District Health Authorities.

Dhok Kazin is a small village categorized as rural area situated in Zone-IV of Islamabad Capital Territory. It has approximately 230 houses with estimated population of 1150 persons. The population of Dhok Kazin has easy access to local private practitioners and to Government hospital facilities.

As Measles is a contagious disease and spread quickly among children under 15 years of age (1), FDSRU Islamabad conducted outbreak investigation by active search of cases in the community to assess magnitude of the outbreak and to suggest / implement control measures for it. For field investigations, an operational case definition was developed and a semi-structured questionnaire was prepared as a case investigation form. For evaluating different risk factors, age and sex matched controls were taken and in order to know the coverage of vaccine in the affected community a vaccine coverage survey form was also prepared.

\section{Methodology}

A case-control study was conducted in Dhok Kazin, Islamabad. All residents of this community having age fifteen (15) years and below were included in this study. Dhok Kazin has approximately 230 houses and total population was estimated to be 1150 persons. All houses were visited door to door by the disease outbreak investigation team. A field operational case definition was constructed as "Sudden onset of fever with maculopapular rash with any of the signs / symptoms like coryza, conjunctivitis, cough, otitis media or pneumonia in any resident of the Dhok Kazin, Islamabad-Pakistan after 20th March to 30th April 2017". A semi-structured questionnaire was prepared as a case investigation form to obtain information about demographic characteristics, clinical features of the disease, hospitalization history, vaccination history and risk factors. Another semistructured questionnaire was prepared for assessment of vaccine coverage of Measles vaccine in the community. All children having age of fifteen (15) years and below were included in this disease outbreak study. All children having age two (02) years and below age were included in vaccine coverage survey. Any child / person above fifteen (15) years age was excluded from the disease outbreak study and any child above two (02) years of age was excluded from vaccine coverage survey. Blood samples were taken from clinically confirmed cases of Measles and sent to National Institute of Health, Islamabad for confirmation of presence of IgM anti-bodies for Measles through Enzyme Linked Immunosorbant Assay (ELISA). Data using case definition was collected on case investigation form. Age and sex matched controls in 4:1 were taken and their data was also collected on case investigation form. Data for vaccine coverage survey was taken on vaccine coverage survey form. Descriptive and inferential methods were used for analyzing the data.

Results

The active search for Measles cases in the affected area carried out on 14th April 2017. The outbreak investigation team visited every house and found 11 more cases of Measles (total no. of cases of Measles $\mathrm{n}=14$ ) with mean age of 39 months (range 08 months to 132 months) and $71 \%$ cases are the age of 36 months and below. Overall attack rate was $1.2 \%$, while most severely affected age-group was $<12$ months $(A R=10.3 \%)$. Amongst cases, $71.5 \%(n=10)$ were female. The spot map of the cases is show in Figure-1. 

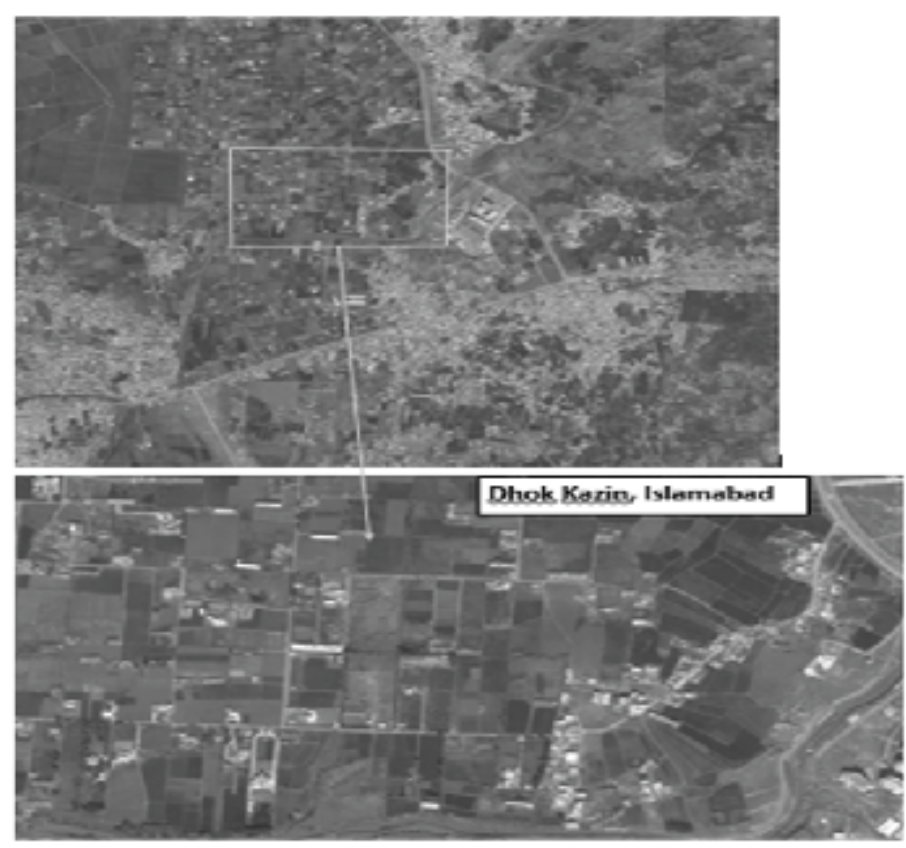

Figure 1: GIS map of the study site

For every case four control $(n=56)$ with matching age and sex were taken from the same community. The literacy rate of mother and father in cases showed that $78.5 \%$ mothers were illiterate while $42.8 \%$ fathers are illiterate. While in controls mothers were found to be more literate $(73.7 \%)$ as compared to fathers $(66.7 \%)$. The demographic characteristics of cases and controls are presented in Table-1. Most severely affected age group was below 12 months having $28.57 \%(n=4)$ cases. Only one child was below the age of 09 months. Figure-2 shows different age groups with respect to gender while Figure-3 shows different age groups for cases and controls.

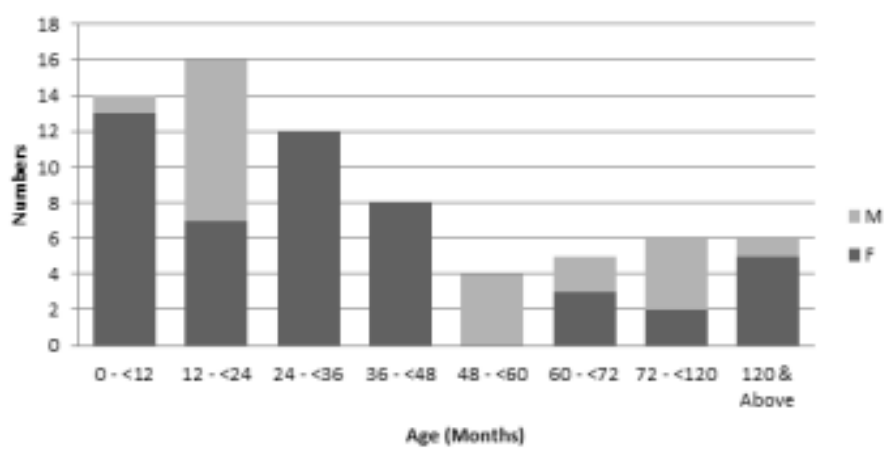

Figure 2: Gender-wise distribution of different age groups

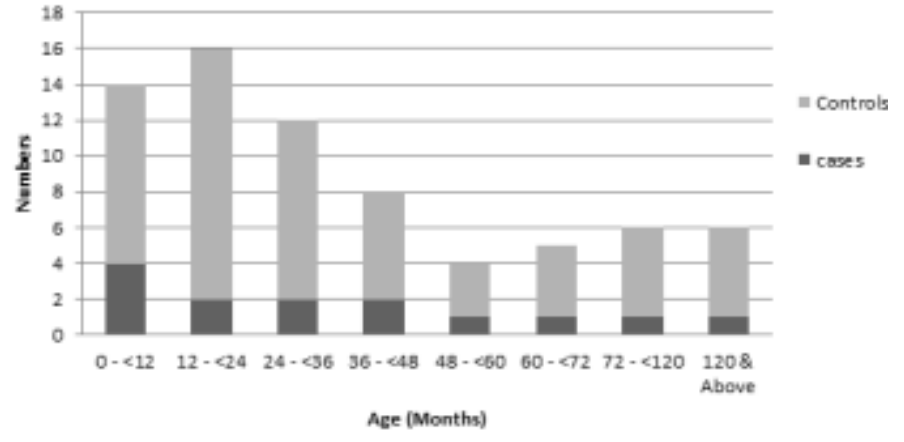

Figure 3: Distribution of cases and controls by age (in months) and numbers

Table 1: Sociodemographic charismatics of the study population

\begin{tabular}{|l|l|l|}
\hline $\begin{array}{l}\text { Socio-Demographic } \\
\text { Characteristics }\end{array}$ & Cases n(\%) & Control n(\%) \\
\hline $\begin{array}{l}\text { Gender } \\
\text { - Male } \\
\text { - Female }\end{array}$ & $\begin{array}{l}\text { (28.5\%) } \\
\text { Mother Education } \\
\text { Illiterate }\end{array}$ & $17(29.8 \%)$ \\
- Literate & $11(78.5 \%)$ & $40(70.2 \%)$ \\
\hline $\begin{array}{r}\text { Father Education } \\
\text { Illiterate }\end{array}$ & $3(21.5 \%)$ & $15(26.3 \%)$ \\
- Literate & $6(42.8 \%)$ & $42(73.7 \%)$ \\
\hline
\end{tabular}

Index case for this outbreak was searched and found that it was a female child aged 36 months with date of onset of symptoms on 23rd March 2017 having a travel history to nearby Burma town, Islamabad. One of her cousin, a male child aged 09 months, living in the same house also visited Burma town with the family and developed symptoms on 25th March 2017. On progression of disease 09 months old male child was admitted to a local private hospital on 30th March 2017 with complications of diarrhea and pneumonia.

The Epicurve for cases was drawn having no. of cases on X-Axis while date of onset of symptoms on Y-Axis. The shape of Epicurve points towards propagated source pattern of the outbreak. The onset of symptoms for index case was 23rd March 2017 while date of onset of symptoms for last cases was 13th April 2017. The peak of outbreak was present on 11th April to 13th April 2017 with onset of symptoms in total six (06) no. of children. Figure-4 shows Epicurve for all the cases.

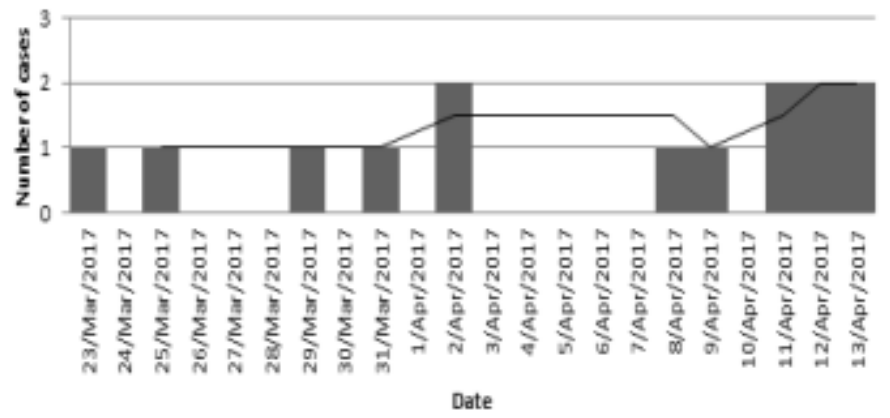

Figure 4: The epicurve for all the cases 
The clinical feature of the cases revealed that all cases $(100 \%)$ had fever, maculopapular rash and coryza while $85 \%$ of cases had cough, $78 \%$ of cases developed conjunctivitis and sore throat, while $42 \%$ of cases reported for koplik's spots. The other clinical features, which can be categorized as complications of Measles, are diarrhea and pneumonia recorded in $42 \%$ and $7 \%$ of cases respectively. Clinical feature pattern of cases is presented in Figure-5.

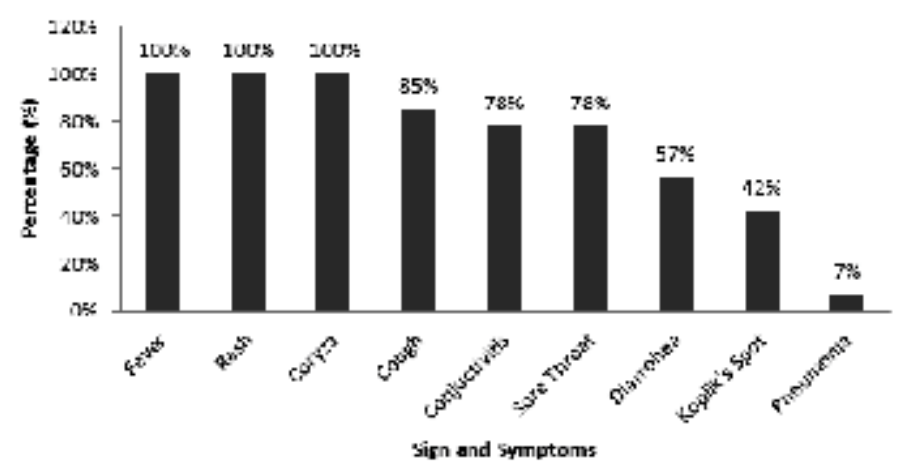

Figure 5: Clinical features of the cases

The immunization status of the cases showed that $35.70 \%$ children were fully immunized, $21.40 \%$ were partially immunized, $14.30 \%$ were not immunized and $28.50 \%$ children were immunized for their age group. While in controls $75.40 \%$ children were fully immunized, $5.20 \%$ were partially immunized and $3.50 \%$ were not immunized. The children who were immunized for their age group were $15.80 \%$. These results are summarized in Figure-6.

$A$ vaccine coverage survey was carried out in the community of Dhok Kazin, Islamabad to know the coverage pattern of different EPI vaccines. The survey results showed that EPI card was available with $65.91 \%$ children $(n=29)$ and BCG scar was present in $84.09 \%$ children $(n=37)$. The first dose of Measles vaccine was given to $70.45 \%$ children $(n=31)$ while second dose of Measles vaccine was given to only $31.82 \%$ children $(n=14)$. The low coverage of second dose of Measles vaccine resulted in compromised immunity of the children and as a consequence Measles outbreak occurred in this area. Attack rate in un-vaccinated children was $14.3 \%$ while attack rate in vaccinated children was $6.7 \%$. Vaccine efficacy calculated was $53 \%$. The results of EPI vaccine coverage survey are summarized in Figure-7.

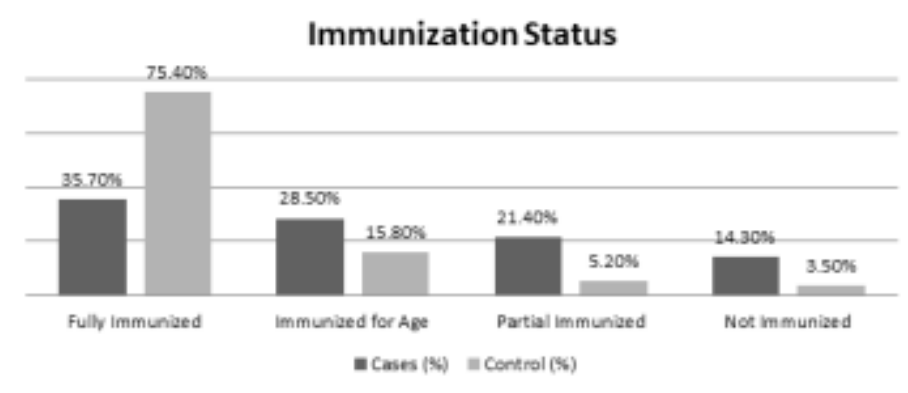

Figure 6: Immunization coverage between the cases and the controls

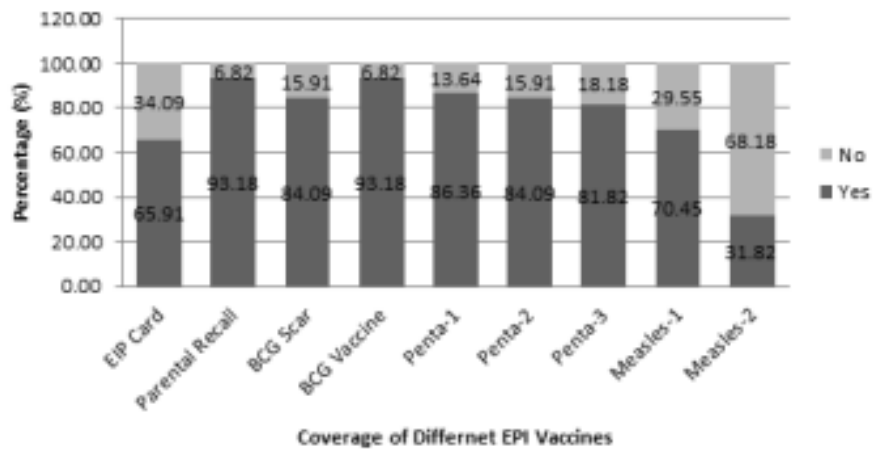

Figure 7: Percent coverage of different EPI vaccines The results for immunization characteristics of cases and controls are presented in Table-2. The results showed that $64.3 \%$ cases had previous history of Measles vaccination while $93 \%$ controls had received Measles vaccine in the past. The vaccination status of children was verified from immunization cards and it was revealed that $50 \%$ of cases had vaccination card available with them while $82.5 \%$ of controls had vaccination cards. During vaccine coverage survey $71.4 \%$ cases responded that Expanded Program on Immunization (EPI) vaccinators had not visited their home for vaccination while $71.9 \%$ controls said that EPI vaccinators visited their homes for vaccination. Parents were asked whether they have any misconception about vaccination or not. The results revealed that parents of $50 \%$ cases had misconception about vaccination while parents of $93 \%$ controls told that they have no misconception about vaccination.

Table 2: Immunization characteristics of cases and controls

\begin{tabular}{|c|c|c|}
\hline Immunization & Cases $n(\%)$ & Control n(\%) \\
\hline $\begin{array}{l}\text { Previous Measles Vaccination } \\
\text { - Yes } \\
\text { - No }\end{array}$ & $\begin{array}{l}9(64.3 \%) \\
5(35.7 \%)\end{array}$ & $\begin{array}{l}53(93 \%) \\
4(7 \%)\end{array}$ \\
\hline $\begin{array}{l}\text { Immunization Card Availability } \\
\text { - Yes } \\
\text { - No } \\
\end{array}$ & \begin{tabular}{|l}
$7(50 \%)$ \\
$7(50 \%)$ \\
\end{tabular} & $\begin{array}{l}47(82.5 \%) \\
10(17.5 \%) \\
\end{array}$ \\
\hline $\begin{array}{l}\text { Vaccinator Not visited } \\
\text { - Yes } \\
\text { - No }\end{array}$ & $\begin{array}{l}10(71.4 \%) \\
4(28.6 \%)\end{array}$ & $\begin{array}{l}16(28.1 \%) \\
41(71.9 \%)\end{array}$ \\
\hline $\begin{array}{l}\text { Misconception } \\
\text { - Yes } \\
\text { - No }\end{array}$ & $\begin{array}{l}7(50 \%) \\
7(50 \%)\end{array}$ & $\begin{array}{l}4(7 \%) \\
53(93 \%)\end{array}$ \\
\hline
\end{tabular}


The odd ratios were calculated for different risk factors associated with Measles outbreak. The identified significant risk factors associated with this outbreak were visit of child to the home of child with Measles illness [OR=19.5, 95\% $\mathrm{Cl}=4.5-84, \mathrm{P}=0.00]$, previous history of Measles vaccination [OR $=7.3,95 \% \mathrm{Cl}=1.6-$ 32.7, $\mathrm{P}=0.003$ ], Mother's education [OR=10.2, $95 \% \mathrm{Cl}=$ 2.5-41.8, $\mathrm{P}=0.00]$, Misconception of parents about vaccination $[\mathrm{OR}=13.2,95 \% \mathrm{Cl}=3.1-57.1, \mathrm{P}=0.00)$, EPI vaccinator not visited homes $[\mathrm{OR}=6.4,95 \% \mathrm{Cl}=1.7-$ 23.4, $P=0.002]$ and non-availability of $E P I$ vaccination cards $[\mathrm{OR}=4.7,95 \% \mathrm{Cl}=1.3-16.4, \mathrm{P}=0.01]$. Reasons for non-vaccination of children were found to be misconception about vaccination (OR=34.8, $95 \% \mathrm{Cl}=5.5-219.7, \mathrm{P}=0.00)$ and mother's illiteracy $(\mathrm{OR}=6.4,95 \% \mathrm{Cl}=1.2-34.8, \mathrm{P}=0.01)$. The results of odd ratios are summarized in Table-3.

\section{Table 3. Odds ratios for measles' risk factors}

\begin{tabular}{|c|c|c|c|c|}
\hline \multicolumn{5}{|c|}{ Risks Factors for Measles Outbreak } \\
\hline Risk Factors & Cases n (\%) & Controls n (\%) & \begin{tabular}{|l|} 
Odd Ratio \\
$(95 \% \mathrm{CI})$
\end{tabular} & P-value \\
\hline $\begin{array}{l}\text { EPI vaccination } \\
\text { Card Availability } \\
\text { - No } \\
\text { - Yes }\end{array}$ & $\begin{array}{l}7(50 \%) \\
7(50 \%) \\
\end{array}$ & $\begin{array}{l}10(17.5 \%) \\
47(82.5 \%) \\
\end{array}$ & $4.7(1.3-16.4)$ & 0.010 \\
\hline $\begin{array}{l}\text { Previous Measles } \\
\text { Vaccination } \\
\text { - No } \\
\text { - Yes }\end{array}$ & $\begin{array}{l}5(35.7 \%) \\
9(64.3 \%)\end{array}$ & $\begin{array}{l}4(7 \%) \\
53(93 \%)\end{array}$ & $7.3(1.6-32.7)$ & 0.003 \\
\hline $\begin{array}{c}\text { Mother Education } \\
\text { - Illiterate } \\
\text { - Literate } \\
\end{array}$ & \begin{tabular}{|l}
$11(78.5 \%)$ \\
$3(21.5 \%)$ \\
\end{tabular} & $\begin{array}{l}15(26.3 \%) \\
42(73.7 \%) \\
\end{array}$ & $10.2(2.5-41.8)$ & 0.000 \\
\hline $\begin{array}{l}\text { Children visit to } \\
\text { House having } \\
\text { measles case } \\
\text { - Yes } \\
\text { - No }\end{array}$ & $\begin{array}{l}11(78.5 \%) \\
3(21.5 \%)\end{array}$ & $\begin{array}{l}9(15.8 \%) \\
48(84.2 \%)\end{array}$ & $19.5(4.5-84)$ & 0.000 \\
\hline $\begin{array}{l}\text { Misconception } \\
\text { about Vaccination } \\
\text { - Yes } \\
\text { - No }\end{array}$ & $\begin{array}{l}7(50 \%) \\
7(50 \%)\end{array}$ & $\begin{array}{l}4(7 \%) \\
53(93 \%)\end{array}$ & $13.2(3.1-57.1)$ & 0.000 \\
\hline $\begin{array}{l}\text { Vaccinator Not } \\
\text { Visited Home } \\
\text { - Yes } \\
\text { - No }\end{array}$ & $\begin{array}{l}10(71.4 \%) \\
4(28.6 \%)\end{array}$ & $\begin{array}{l}16(28.1 \%) \\
41(71.9 \%)\end{array}$ & $6.4(1.7-23.4)$ & 0.002 \\
\hline
\end{tabular}

\begin{tabular}{|c|c|c|c|c|}
\hline $\begin{array}{l}\text { Reasons for Non- } \\
\text { Reason }\end{array}$ & $\begin{array}{l}\text { Not Vaccination of Childre } \\
\text { Measles Previously } \\
\text { n (\%) }\end{array}$ & \begin{tabular}{|l|} 
Vaccinated for \\
Measles Previously \\
n (\%)
\end{tabular} & $\begin{array}{l}\text { Odd Ratio } \\
(95 \% \mathrm{CI})\end{array}$ & $\begin{array}{l}\text { P- } \\
\text { Value }\end{array}$ \\
\hline $\begin{array}{l}\text { Misconception } \\
\text { about Vaccination } \\
\text { - Yes } \\
\text { - No } \\
\end{array}$ & $\begin{array}{l}6(75 \%) \\
2(25 \%) \\
\end{array}$ & \begin{tabular}{|l}
$5(8 \%)$ \\
$58(92 \%)$ \\
\end{tabular} & $34.8(5.5-219.7)$ & 0.000 \\
\hline $\begin{array}{c}\text { Mother Education } \\
\text { - Illiterate } \\
\text { - Literate }\end{array}$ & $\begin{array}{l}6(75 \%) \\
2(25 \%)\end{array}$ & $\begin{array}{l}20(32 \%) \\
43(68 \%)\end{array}$ & $6.4(1.2-34.8)$ & 0.014 \\
\hline
\end{tabular}

\section{Discussion}

The results of this study showed that affected age group of children is from 08 months to 132 months with most affected age group of children less than 12 months of age. These findings are consistent with fact sheet of World Health Organization about Measles (8). A Measles outbreak investigation was carried out during 2014 in District Pishin, Baluchistan and it was also found that maximum affected age group of children were less than 05 years of age (10).

It was seen in the results of current study that females are most affected as compared to males. Although Measles virus is not selective for gender and affects both genders equally but possible reason for it is that females are under privileged gender group particularly in lower socio-economic class in Pakistan. The girls mostly remain at home and help in house hold chores. If they come in contact with any case of Measles then there are more chances that Measles spread among other members present in the home because of continuous presence of case at home and also because of clustering and crowding of females at home. It is also possibility that the girls in lower socio-economic class did not get Measles vaccination. Because of this they have more chance of contracting Measles virus from already infected children.

Measles vaccine is included in routine immunization of EPI in Pakistan and its first dose is given at the age of 09 months while second dose, as a booster dose, is given at the age of 15 months. EPI issues vaccination card to children at birth for maintenance of EPI vaccination record. The availability of EPI vaccination card at home confirms the immunization status of children and during EPI vaccine coverage survey in this study it was found that vaccination status of $50 \%$ cases cannot be confirmed as compared to controls where vaccination status of $17.5 \%$ children was not confirmed due to nonavailability of EPI vaccination cards. The odd ratio for this risk factor is clearly suggestive that chances of development of Measles in children whose vaccination status cannot be confirmed by availability of vaccine card is higher as compared to children whose vaccine status can be confirmed by availability of EPI vaccination card. Similarly the results of previous Measles vaccination revealed that history of previous Measles vaccination among control group is higher $(93 \%)$ as compared to cases $(64.3 \%)$ and also its odd ratio is suggestive that chances of development of Measles in cases is higher than controls. These results are in line with results of a study carried out in USA by reviewing published articles to evaluate the association between vaccine delay, refusal, or exemption and the epidemiology of Measles in outbreaks in USA. This study mentioned that non-vaccinated population had experienced Measles outbreaks while the vaccinated population remained safe during course of these outbreaks (12).

Literacy rate of mothers has positive impact on health of children and prevention of disease. In this study results have shown that mothers of higher number of cases were illiterate as compared to controls and odd ratios suggested that chance of development of Measles in children of illiterate mother is higher as compared to children of literate mothers. These results are in accordance with a study carried on Demographic \& Health Survey Data of Pakistan and India. According to it illiterate mothers immunize their children less than literate mothers. Hence unvaccinated children of illiterate mothers are greater risk of getting disease (13). 
Misconception of parents serves as main reason for nonimmunization or partial immunization of children. This misconception is due to many reasons like religious beliefs, cultural beliefs, anecdotes, etc. But these misconceptions create a vulnerable group of children with no immunity or partial immunity against diseases. In this study it was found that $70.45 \%$ children received first dose of Measles vaccine and only $31.82 \%$ second dose or booster dose of Measles vaccine and odd ratio for misconception of parents about vaccination was suggestive that chances of development of Measles in the children of parents who have misconception about vaccination was higher as compared to its comparison group of controls. The results of this study are in accordance with a study carried out in India to asses maternal knowledge and perception about routine immunization and it was found in it that misconception of mothers was the main reason for non-immunization and partial immunization of children (14).

It is well documented that transmission of Measles virus occur in susceptible population when they come in close contact with cases at household, schools or at healthcare facilities (3). The results of this study showed that chances of development of Measles in children who visited another house with Measles case was higher than then children who did not visit the house having Measles case. In United States a Measles outbreak was investigated in fully immunized population of secondary school and the results of this study revealed that Measles outbreak could occur in fully immunized population and the possible reason was that when susceptible population came in contact with cases more frequently then chances of transmission of Measles virus increased and chances of development of Measles even among fully immunized population also increased (15).

Routine immunization of Measles vaccines is carried out on designated EPI centers. Additionally vaccinators also go to community for vaccination of children as part of outreach activities. It was found in study that more cases reported about no visit of vaccinator to their homes as compared to control group. The odd ratios suggested that chance of development of Measles is more in population of children where vaccinator did not go to home for vaccination of children than in population where vaccinator visits children at home for vaccination. These results of current study are in accordance with the results of Measles outbreak occurred in Baluchistan in 2014 in which it was found that Measles was high in unimmunized children and one of the reason for it was that EPI facility was far away and vaccinator did not visit home as part of outreach activity for Measles vaccination (10).

\section{Conclusion}

It is concluded from investigations of this outbreak that most affected age group of children was below 12 months of age and the most affected gender group were females. The EPI vaccine coverage for Measles is low for first dose and it even decreased drastically for second dose.

\section{References}

1. Centers for Disease Control and Prevention. Measles. Epidemiol Prev Vaccine-Preventable Dis 13th Ed [Internet]. 2015;209-29. Available from: http://www.cdc.gov/vaccines/pubs/ pinkbook/meas.html

2. Durrheim DN, Kelly H, Ferson MJ, Featherstone D. Remaining measles challenges in Australia. Med JAust. 2007;187(3):181-4.

3. Rota PA, Moss WJ, Takeda M, de Swart RL, Thompson KM, Goodson JL. Measles. Nat Rev Dis Prim [Internet]. 2016;2:16049. Available from: http://www.nature.com/articles/ nrdp201649

4. Goodson JL, Seward JF. Measles 50 Years After Use of Measles Vaccine. Vol. 29, Infectious Disease Clinics of North America. 2015. p. 72643.

5. Galindo BM, Concepción D, Galindo M a, Pérez A, Saiz J. Vaccine-related adverse events in cuban children, 1999-2008. MEDICC Rev [Internet]. 2012;14(1):38-43. Available from: http://www.ncbi.nlm.nih.gov/pubmed/22334111

6. World Health Organization. GLOBAL MEASLES AND RUBELLA: Strategic Plan 2012-2020 [Internet]. World Health Organization. 2012. 44 p. Available from: http://www.who.int/immunization/documents/co ntrol/ISBN_978_92_4_150339_6/en/

7. Vos T, Barber RM, Bell B, Bertozzi-Villa A, Biryukov S, Bolliger I, et al. Global, regional, and national incidence, prevalence, and years lived with disability for 301 acute and chronic diseases and injuries in 188 countries, 1990-2013: A systematic analysis for the Global Burden of Disease Study 2013. Lancet [Internet]. 2015;386(9995):743-800. Available from: http://dx.doi.org/10.1016/S01406736(15)60692-4

8. World Health Organization. Measles. WHO Media Cent [Internet]. Available from: http://www.who.int/mediacentre/factsheets/fs28 6/en/

9. Pan American Health Organization / World Health Organization. Measles elimination in the PAHO/WHO Media Center. [Internet]. Available from: http://www.paho.org/hq/index. php?option=com_content\&view $=$ article\&id $=125$ 26\&ltemid $=4072 \overline{1}$ \&lang=en

10. Saeed A, Butt ZA, Malik T. Investigation of Measles Outbreak in a District of Balochistan Province, Pakistan. J Ayub Med Coll Abbottabad [Internet]. 2015;27(4):900-3. Available from: http://jamc.ayubmed.edu.pk/index.php/jamc/art icle/view/365

11. Sadaf R. Measles Epidemic in Pakistan?: In 
Search of Solutions. 2014;4(1):1-2.

12. Phadke VK, Bednarczyk RA, Salmon DA, Omer SB, Health G. Diseases in the United States?: 2016;315(11):1149-58.

13. Subhani S, Yaseen R, Khan MA, Jeelani G, Fatima R. Impact of Mother's Education on Child Immunization: A Comparative Study of India and Pakistan. J Financ Econ [Internet]. $2015 ; 3(3): 51-4$. Available from: http://pubs.sciepub.com/jfe/3/3/1/index.html

14. Manjunath U, Pareek RP. Maternal knowledge and perceptions aboutthe routine immunization programme--a study in a semiurban area in Rajasthan. Indian J Med Sci [Internet]. 2003;57(4):158-63. Available from: http://www.ncbi.nlm.nih.gov/pubmed/14510348

15. Gustafson TL, Lievens AW, Brunell PA, Moellenberg RG, Buttery CM, Sehulster LM. Measles outbreak in a fully immunized secondary-school population. N Engl J Med. 1987;316:771-4. 